\title{
Learning to be Agile in Medical Teaching
}

\author{
Iain Doherty $^{1}$ - Neel Sharma ${ }^{2}$ - Darren Harbutt ${ }^{3}$
}

Published online: 23 June 2015

(C) International Association of Medical Science Educators 2015

\section{Background}

Technological change is a constant. At the moment, we are seeing a significant shift from desktop devices to mobile devices. Of particular note, there is the shift towards the use of tablets that have been termed "agile devices" [1] because of their unique affordances. For example, they are more portable than laptops, start up in a fraction of the time, have a significantly longer battery life and can be populated from a range of thousands of applications. Penetration of these devices in the market place is set to exceed the penetration of desktop devices [2]. We are also seeing a shift from applications installed on computers to cloud-based computing. In reality, this means the provision of applications as a service rather than as a product. For example, Google Drive offers an online cloud-based office suite and Google Market Place provides hundreds of Web-based applications. In addition to the shift to mobile, cloud-based computing, our understanding of the delivery of educational experiences is also shifting significantly. MOOCs have called the predominant educational paradigm into

Iain Doherty

iaindoherty@yahoo.com

1 Learning and Teaching Innovation, Professional and English Programs, Navitas, Wynyard Green, Level 4, 11 York Street, Sydney, NSW 2000, Australia

2 Division of Gastroenterology and Hepatology, National University Hospital, Singapore, Singapore

3 eLearning Pedagogical Support Unit, Centre for the Enhancement of Teaching and Learning, The University of Hong Kong, Hong Kong, China

question. Apple provides educational content through iTunes $\mathrm{U}$ and Google provides the YouTube Edu Channel.

Whilst we are seeing significant educational changes as a result of the changing technological landscape, our focus in this paper is tablet devices. The reason for this is that tabletswhether Apple or Android - are ubiquitous and they are set to overcome desktop devices in terms of market penetration. This fact presents both a challenge and an opportunity. In terms of challenge, educators need to be aware that students are increasingly mobile with anywhere any time access to information. Beyond this, they can communicate and collaborate anywhere and at any time allowing for group-based learning to take place "on the go". As the result of the proliferation of applications through iTunes and through the Google Market Place, educators have the opportunity to enhance the quality of teaching and learning. Here, the quality is understood in terms of the extent to which any particular course enables to achieve the intended learning outcomes whilst at the same time giving them a positive educational experience. We will return to this point at the end of our paper when we discuss pedagogy.

Students and doctors can make use of tablets to aid learning. At the most basic level, there are medical eBooks that can be read on a tablet (http://www.ebooks.com/subjects/ medicine/). Inkling is particularly strong in terms of the range of medical subjects covered by their eBooks (https:// www.inkling.com/store/category/medicine/). Students can also use eLearning-based modules [3]. This takes learning a step further with the inclusion of online assessment. This aligns with the classic dictum that assessment drives learning. An additional advantage with these applications is that feedback is immediately available. This contrasts with the typical examination situation for medical students where the provision of feedback is still limited leaving students wondering exactly what they "got wrong" and why they got it wrong 
[4]. Tablet applications therefore have the potential to support the learning of any training/practising medic without the need for teacher presence.

The use of simulations in medical training has a long history [5]. Simulations can provide for instant feedback and are particularly advantageous in assessing individuals in an acutebased scenario where activity can be monitored in real time and in a controlled setting avoiding concerns of patient safety. The advent of tablets brings another dimension to the use of simulations in teaching. Simulations can now be accessed anywhere and at any time. For example, the ALSi Patient Condition System (http://www.isimulate.com/) runs patient simulations based on instructor controlled patient parameters. There are also simulations for anaesthesia that run on tablets (http://anesoft.com/) along with tablet applications that replicate patient monitors (http:// healthysimulation.com/2465/simulation-monitor-iphoneapp/) and ECG simulations (http://ecg-simulator.com/).

Technology also allows for permanent capture of an individual's competency through the use of online portfolios [6]. Candidates can undertake reflective-based exercises in addition to capturing evidence of knowledge, skills and behaviours relevant to a specific competency-based activity. It is of course entirely possible to maintain competency records on a desktop computer or a laptop. However, tablets can be carried throughout the day and used by students/doctors during "down time". Some applications link learning directly to evidencing professional competency. For example, learners who use NEJM Knowledge+(http://knowledgeplus.nejm. org/) can earn ABIM MOC points.

Finally, doctors are required to consult latest evidencebased guidelines on a daily basis in order to ensure that they have the most up to date and accurate information for patient care. Platforms such as UpToDate (http://www.uptodate.com/ home) and eMedicine (http://emedicine.medscape.com/) are just two examples of online resources that are widely accessed, enabling access to information to take place at the point of care. There are mobile specific devices to support evidenced-based practice and patient care. UpToDate provides a mobile application for each tablet operating system. Epocrates (http://www.epocrates.com/support/) is a dedicated application providing information on drugs/drug interactions along with medical information and research news. Students need to be introduced to these applications so that they are ready to take their place in a mobile enabled medical profession.

\section{The Pedagogy Behind Tablet Devices}

Tablet devices are about more than the availability of specific applications and services. They represent an entirely new way of working, learning, communicating and collaborating. Cloud services are at the heart of this revolution. In essence anything that is done on a tablet device is immediately available on any other device. For example, notes taken on a tablet become immediately available on a desktop computer. Notes edited on the desktop computer are immediately synchronized with the tablet device. Furthermore, these notes can be shared with colleagues using a variety of methods from giving access to the notebook to emailing a single note. This opens up possibilities for collaboration and information sharing. Learning that is undertaken using a device specific application is also available through a browser interface on a desktop or laptop computer. This makes learning truly flexible as it can occur anywhere and at anytime. The advantage for busy doctors is obvious.

Tablet devices obviously have affordances for teaching, learning and medical care. At the same time, however, we need to pay attention to pedagogy. Certainly, tablet applications can present students with information and test them using multiple choice quizzes. However, being able to recall facts does not make one a doctor. Being a doctor involves having the ability to apply knowledge to clinical cases. If tablets are to be really beneficial in medical education then we need to see more applications that present "authentic" learning scenarios. This means that we need more applications that present learners with cases or problems that require the application of knowledge to realistic patient care problems. The clinical reasoning process needs to be central to learning. There are applications that meet the pedagogical standards we are talking about, for example the clinical pattern recognition application (http://appcrawlr.com/ios/clinical-patternrecognition-lo) and the diagnosis application for testing clinical reasoning (http://appcrawlr.com/ios/prognosisyourdiagnosis). However, these applications are by no means ubiquitous.

Some teachers may demonstrate concern with the ever increasing use of tablet devices and their potential role or lack thereof. It is important to note that even though such a platform allows for user control of their learning through various means, the teacher is not necessarily redundant. The aforementioned Google Drive-based intervention can ensure teachers' monitor student information sharing and feedback accordingly enhancing the engagement process. In addition, learning analytics data capture can allow teachers to observe their students' progress and adapt learning objectives/ curricula material according to their needs. Adaptive learning can also ensure teacher presence in many ways with assessment of students' knowledge gaps and an automated approach designed to focus on those areas in more detail.

\section{Closing Remarks}

The prevalence of tablet devices is a given, and the range of medical applications is steadily increasing. These devices 
present a great opportunity for teachers, students and for practising health professionals. However, their use must be driven by pedagogical considerations to ensure that technologies are employed in the service of high quality teaching and learning. This in turn must translate into better outcomes for patients. With these points in mind, it is time to become agile in our medical teaching.

\section{References}

1. Wilson I. The agile space. The iPad in education. 2012. Available from: http://www.ipadineducation.ianwilson.biz/iPad_in_Education/ The_Agile_Space.html.
2. Deepend. Australian mobile device ownership and home usage report. 2014. Available from: http://www.deepend.com.au/downloadwhite-paper-device-usage-in-the-home.

3. Walsh K, Rafiq I, Hall R. Online educational tools developed by heart improve the knowledge and skills of hospital doctors in cardiology. Postgrad Med J. 2007;83(981):502-3.

4. Sharma N. The importance of real-time feedback in undergraduate assessments. Acad Med. 2013;88(11):1592-3.

5. Doherty I, Hansen M, McCann L, Oosthuizen G, McHardy K, Greig S, Windsor J. Simulated learning for clinical skill acquisition and retention: report on a research project with trainee medical interns. 2008. Available from: http://www.editlib.org/noaccess/29197/.

6. Van Tartwijk J, Driessen EW. Portfolios for assessment and learning: AMEE guide no. 45. Med Teach. 2009;31(9):790-801. 